\title{
Trend of the Research on Public Funded Projects
}

Dpen Access

\author{
Honglei $\mathrm{Yi}^{*}$ and Yousong Wang
}

School of Civil Engineering and Transportation, South China University of Technology, Guangzhou 510640, China

\begin{abstract}
As one of the main means to deliver service, Public Funded Projects (PFPs) always play a vital part in the development of the human society. Accordingly, research interests concerning PFPs from the construction industry have led to a great number of published papers during the past decades. Aimed at identifying the emerging research trend of researches addressing PFP issues, this study obtained target publications from selected international journals, and analyzed those articles in terms of the number of annual publications, authors and affiliations as main contributors, popular research themes, and preferred research methods. This study indicated that the number of PFP articles have been increasing, which could imply the growing importance of PFPs to the construction industry at large. What is more, the findings suggest that researchers from the United States are the most active in this discipline, followed by those from the United Kingdom, Australia, China, Hong Kong and Spain. And the origins of productive affiliations follow a similar way. With respect to emerging hot research topic, integration research, delivery method, sustainable exploration, governance issue, financial concern, performance study, risk management and decision-making challenges tend to attract more concerns of researchers within this discipline. Meanwhile, it was also found that the target articles of this study can be catalogued into three groups, field report, theoretical analysis, and quantitative calculation respectively. In addition, more vigorous modeling and simulation techniques such as stochastic frontier regression modeling and fuzzy synthetic evaluation simulation have been adopted in related researches. Moreover, investigations of content analysis also exhibit that sustainability should be the essential characteristic of PFPs, but there is still a long way to go concerning current sustainability performance of most PFPs. More relative research efforts are needed to ensure a sustainable development of PFPs as well as the construction industry.
\end{abstract}

Keywords: Public Funded Projects, construction industry, trend of the research, sustainability.

\section{INTRODUCTION}

Public Funded Projects (PFPs) are essential in the human society since they are an important source of public services provided by the governments to the people. Meanwhile, they are active motives to the economic growth [1]. They are also of value to the construction industry since they significantly contribute to the output value of the industry. In response to the facts, a great number of articles related to PFPs have been published in academic journals all over the world for the past decades. As these publications promote the development of relative research, they also challenge the researchers possessing an interest in this discipline to gain a quick but wide perspective of this topic. However, reviewing existing literatures always means a lot to the researchers and practitioners in this area by helping them to gain the access to current progress, sharing their research findings, and making further advancement from where previous studies stopped [2].

Academic journals are usually thought to be useful source of literature. For the researchers, it provides state-ofart research findings that are not only critical for the career, but also necessary to assist them to produce desired publications [3]. Therefore, systematically and thoroughly studying the literatures published in relevant academic journals will

*Address correspondence to this author at the School of Civil Engineering and Transportation, South China University of Technology, Guangzhou 510640, China; Tel: 86-15920481699; Email: yihonglei1122@gmail.com have positive impacts on understanding the research development and seizing future trends [4].

Many researchers have conducted such analysis in their own fields, such as Tsai and Lydia Wen [4] in science education, $\mathrm{Ki}$ and Shin [5]in public relations, and Pilkington and Chai [6] in general management. In the discipline of construction management, Bresnen and Marshall [7] made their contribution to the debate of the partnering approach by seeking and validating the link between partnering and cultural change of construction industry through literature review, and obtained the conclusion that the approach to the implementation and development of partnering should be more realistic and practical which could only be achieved by full appreciation of the effects of organizational complexities. Al-Sharif and Kaka [8] analyzed the publications related to PFI/PPP (private finance initiative/public-private partnership) between 1998 and 2003 in selected construction journals to present the coverage of topics in the concerned discipline, and the gaps to be filled in the future research efforts. They also pointed out that during this period the importance of PFI/PPP as well as the level of actual activities associated was not properly reflected in the number of published academic articles. In addition, inspired by their study, Ke et al. [2] continued to examine the PPP publications from 1998 to 2008 in seven top-ranked construction journals in terms of the number of PPP articles published annually, the writers' contribution, the research interests in their studies, and thus the research trend of PPP. In the research of Yuan and Shen 
[9], published papers addressing construction and demolition waste management in eight major international journals between 2000 and 2009 were systematically examined to present the latest trend in this research area. It was found that the importance of human factors in this discipline had emerged to be a new hot topic.

For the past decades, other than the function of delivering public services, PFPs have been constantly playing an important role as a supporting pillar to the human society, especially when financial crisis and economic depression hits the system. However, an increasing number of problems in the process of delivery and maintenance of PFPs have been reported. On the other hand, it is found that there is merely systematic content analysis of publications addressing PFPrelated issues to reveal research development in this area from academic construction journals. It is therefore of value to conduct a research in such a fashion. This study is aimed at reviewing articles published in selected academic construction journals from 2002 to 2012 to demonstrate the latest research development and emerging research trend in PFPs by addressing the following questions:

1. How did the annual number of PFP publications vary during the period of 2002-2012?

2. Who were the active contributors in PFP topic during the period of 2002-2012?

3. What were the main types of PFP papers and methods adopted during the period of 2002-2012?

4. How did the research themes of those PFP publications develop during the period of 2002-2012?

\section{PUBLIC FUNDED PROJECTS}

Public sector is essential in modern society, since there are continuous demands which can't be met through the economic activities of the market. In response to those demands, the government needs to provide public services through the delivery and operation of PFPs. In fact, PFPs have always been a source of policy concern [10]. For example, in China, The Decision on Reform of Public Investment System was issued by the State Council to promote the implementation of Agent Construction System for non-profit PFPs. When encountered the rapid economic downturn, the whole society will rely more on PFPs to create jobs and spur economic activity as quickly as possible [11]. One of the convincing evidences lies in the following fact. In 2009, responding to the Great Recession, the American Recovery and Reinvestment Act decided to provide a total funding of USD 130 billion to the construction industry to support various projects, among which USD 19.2 billion was meant to be spent on PFPs $[12,13]$. Apart from this, in South Africa, it is the belief of the positive impact of PFP investment on economic growth that put forward a number of government policies such as Accelerated Shared Growth Initiative for South Africa [14]. The policy aims to energize the national economy through potential multiplier effect public sector possesses to the extent that the objective of $6 \%$ national economic growth becomes achievable. Normally, PFPs play an obvious role in the development of infrastructure in developing countries. Fig. (1) demonstrate the annual public investment of infrastructure projects in developing countries between 1991 and 2011 [15].

From country to country, the demands for PFPs of both local and state governments are significant. Those projects are desired for a variety of purposes including basic services, transportation, utilities, and economic development [16]. Given limited available resources on materials, workforce, and finance, projects are implementation tools of policies to accomplish development programs [17]. There are several important issues to be considered when utilizing a country's resources for development, such as how to select the right projects with suitable criterion, how to prepare and complete them with satisfying performance, and afterwards how to operate and maintain them in a sustainable way [18].

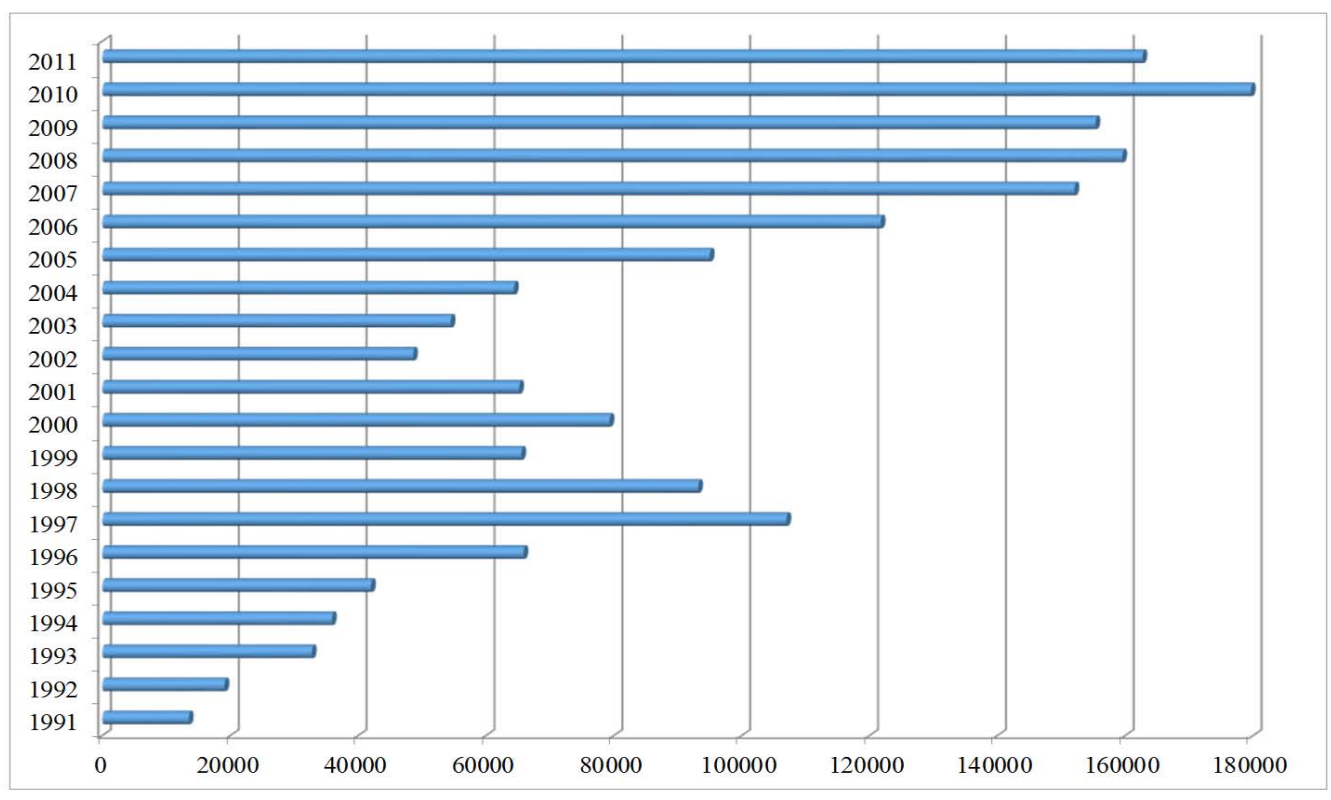

Fig. (1). Annual Public Investment (USD in million) of Infrastructure Projects in Developing Countries in 1991-2011 [15]. 
One of the characteristics of PFPs is their costs significantly exceed those of normal projects, because they are onetime, much larger, and have relatively long-term implications [16]. Practitioners and researchers have established recommended practices for costs planning and management in PFPs to assist in decision making. There are also many studies addressing transparency, efficiency, accountability, and public participation. However, the ability of the governments to fund PFPs is affected by financial constraints. Not surprisingly, the relationship between capital spending and economic conditions as well as the state of governmental resources is evident by previous research [19]. Public investment has long been found to not keep up with needs [20]. In effect, underinvestment is among one of the major reasons which create an unacceptable situation in PFPs, especially in power, transport, and water-related projects. Contending with underdevelopment and poverty is being hindered by the deficiency in the process of delivery, operation and maintenance of PFPs. Coping with this predicament, Public-Private Partnership was introduced in 1997 to effectively deliver value for money public projects and services [2].

The differences in many ways between public and private sector projects are pointed out by several studies [21, 22]. It is clear that diverse demands and perceptions exist in the private and public sectors. Being neglected, some particular issues relating to PFPs are not given due attention in the current study and research [23]. The missing of such exploration leads to various problems in international PFPs.

In theory, PFPs should be designed with objectives that are consistent with the development strategy of local community and the country at large. However, based on investigation of the practice, those objectives tend to be stated ambitiously, with achievements which are believed to be below the initial plan [24]. In the study of Klakegg and Haavaldsen [25], objectives of PFPs are often found to be exaggerated. One of the major reasons is that planners and decision makers don't investigate the viabilities of those objectives before setting them. Overambitious planning favored launching mega PFPs and these biases are proved to be costly and unsuccessful. As Samset [26] indicated, a PFP without relevancy and sustainability is a failed project which should have been rejected at the beginning or terminated on verification. Similarly, some leading stakeholders are tend to be ignored in the project selection and decision-making processes due to personal or political reasons, which results in the widespread low-commitment of stakeholders affecting the sustainability of PFPs [24].

In addition, there are other problems on PFPs reported in previous study, such as corruption [27], financial evaluation [28], risk allocation and sharing [29], etc. The worldwide challenges encountered by international practices have blocked the future development of PFPs. To deal with this bottleneck, it is necessary to carefully investigate into current studies in this discipline by systematically analyzing the content of research papers published in major construction journals recently. Hereby, this study is of value to scholars and practitioners by assisting them to comprehend the research status of PFPs better.

\section{RESEARCH DESIGN AND DEVELOPMENT}

\section{Identification of Selected Academic Journals}

To fulfill the research objectives introduced above, this study began with identifying the academic journals with most publication concerning PFP issues. To obtain this list, searching with scholar search engine is a good option. First, the scholar search engine "Scopus" was chosen to conduct a comprehensive search in the fields of "titles/abstract/keyword". There are fair reasons to adopt Scopus as the search engine. First, it is established and run by Elsevier, one of the leading publishers of academic journals in the world, supported by its qualified database. Second, it is believed to perform better than other engines including PubMed, Web of Science, Google Scholar, etc in terms of coverage and accuracy [30]. Third, Scopus is quite popular among researchers on construction industry $[2,9]$. In the subject areas of "Physical Sciences" and "Social Sciences", and with the document type of "article or review", public funded projects, public works projects, public sector projects, public investment, projects funded by public financing and other relative keywords were included in the initial search to acquire papers with these specific terms in the title, abstract, or keywords. The scope was further refined by keyword specification with "construction". The complete search code is listed as follows:

TITLE-ABS-KEY (public funded projects) OR TITLEABS-KEY (public works projects) OR TITLE-ABS-KEY (public sector projects) OR TITLE-ABS-KEY (public investment) OR TITLE-ABS-KEY (projects funded by public financing) AND TITLE-ABS-KEY (*construction) AND DOCTYPE (ar OR re) AND SUBJAREA (mult OR ceng OR CHEM OR comp OR eart OR ener OR engi OR envi OR mate OR math OR phys OR mult OR arts OR busiOR deci OR econ OR psyc OR soci) AND PUBYEAR > 2001 AND PUBYEAR < 2013 AND LIMIT-TO (SUBJAREA, "ENGI") OR LIMIT-TO (SUBJAREA, "SOCI") OR LIMIT-TO (SUBJAREA, "BUSI") OR LIMIT-TO (SUBJAREA,"ENVI") OR LIMIT-TO (SUBJAREA, "ECON") OR LIMIT-TO (SUBJAREA, "ENER") OR LIMIT-TO (SUBJAREA, "ENGI") OR LIMIT-TO (SUBJAREA, "SOCI") OR LIMIT-TO (SUBJAREA, "BUSI") OR LIMIT-TO (SUBJAREA, "ENVI")OR LIMIT-TO (SUBJAREA, "ECON") OR LIMIT-TO (SUBJAREA, "ENER") OR LIMIT-TO (SUBJAREA, "DECI")) AND (LIMIT-TO (LANGUAGE, "English").

The outcome of the search demonstrated that the Construction Management and Economics (CME), the Journal of Construction Engineering and Management (JCEM), the Transportation Research Record (TRR), the International Journal of Project Management (IJPM) and the Engineering Construction and Architectural Management (ECAM) have published the most research articles addressing PFP issues, and thereby were identified as selected academic journals for further study. It is worth noting that CME, JCEM, IJPM and ECAM are highly reputed construction management journals according to the ranking of Chau [31], while TRR keeps up with edge-cutting research relating to transportation and supported infrastructures. This fact reinforces that the target journals of this study are of good quality. 


\section{Selection of Target Papers}

The search result from above step comprised 1072 research papers. Among those papers, not all of them should be taken into considerations in this study. The reason is that some papers happened to meet the specifications of the search code when they were cutting through to their focuses which are irrelevant to this study. Those papers were excluded in this stage.

According to the selected journals, target papers were obtained through visual examinations and more comprehensive search within those journals. Publications in those journals that focus on concerning PFP-related issues were selected, and papers belonging to the broad categories of "articles in press ", book review ", discussions and closures, "editorial" and "letter to the editor" were excluded as well. As a consequence, this study identified 159 articles published in the selected journals discussing PFP as target papers.

\section{Examination of Target Papers}

The target papers were given a careful visual examination and sifting by means of content analysis. Annual number of published PFPs papers, active authors and their contributions, research centers and origins, as well as research themes and trend in PFP was figured out through an in-depth content analysis of selected papers.

When calculating and ranking the contribution of each research origin and centre as well as author, a quantitative method was necessary. In previous studies, there were two different fashions. In the research of Al-Sharif and Kaka [8], one fashion came out that each author in a multi-author publication was rewarded identical score to the single author in a paper. On the other hand, Tsai and Lydia Wen [4], Lee et al. [3], and Ke et al. [2] adopted a formula proposed by Howard et al. [32] to differentiate the contribution of each author in a multi-author article. In this study, to acquire more accurate result, contribution analysis was conducted in the latter approach. Each publication was given one point, no matter how many authors there were. If more than one author participated in the producing of the paper, the one point was divided into corresponding parts for each author. And this one point was distributed to the authors according to the formula below:

$$
\text { Score }=\frac{1.5^{\mathrm{n}-\mathrm{i}}}{\sum_{\mathrm{i}=1}^{\mathrm{n}} 1.5^{\mathrm{n}-\mathrm{i}}}
$$

Where $n$ denotes the number of authors contributing to the paper, and $i$ is the order of each specific author.

Applying the above formula, a detailed distribution of score to each author is presented in (Table 1). By doing it in this way, each individual author was rewarded fairly, with the assumption that the authors ranking higher normally have contributed more than those in lower order in a multi-author paper.

In addition, the target papers were grouped by the research themes they focus on and the research methodologies they adopt respectively. Such analysis not only presents the topics which have been investigated in previous researches, but also demonstrates how the research themes develop for the past decades. What's more, the results also imply the emerging research trend for the future.

\section{DISCUSSION AND RESULTS}

\section{Holistic View on PFP Papers Published in 2002 to 2012}

The overall number of published PFP papers identified by Scopus was 1024, with an increasing trend from 46 in 2002 to 116 in 2012. This trend reinforced that PFP as a research topic is obtaining continuously increasing attention during 2002 to 2012. (Table 2) illustrates the annual number of PFP publications meeting the requirements of initial search code and in each target journal between 2002 and 2012.

In fact, there are 160 different journals which were found to have published the identified 1072 publications relative to PFPs during 2002 to 2012. As described in the "Research Design and Development" section, the journals of CME, JCEM, TRR, IJPM, and ECAM were identified as the selected journals because they have published the most PFP papers with the number of $45,39,30,23$ and 22 respectively. It can be seen that the annual number of target papers remains relatively steady for the investigation period, so is for each selected journals except TRR. What's more, the proportion of PFP papers in the total publications of each selected journal is quite significant. For example, in 2003, CME published 72 papers in total, which means $5.56 \%$ of them were addressing PFPs. Similar facts exist for each selected journal every year. Since CME, JCEM, IJPM and ECAM are all high-ranked construction management journals, it can be concluded that PFPs have continuously been among the major concerns of mainstream researches in construction

Table 1. Score Matrix for Multi-Author Papers

\begin{tabular}{|c|c|c|c|c|c|}
\hline \multirow{2}{*}{ Order of Specific Author } & \multicolumn{5}{|c|}{ Number of Authors } \\
\hline & 1 & 2 & 3 & 4 & 5 \\
\hline 1 & 1 & 0.6 & 0.47 & 0.42 & 0.38 \\
\hline 2 & & 0.4 & 0.32 & 0.28 & 0.26 \\
\hline 3 & & & 0.21 & 0.18 & 0.17 \\
\hline 4 & & & & 0.12 & 0.11 \\
\hline 5 & & & & & 0.08 \\
\hline
\end{tabular}


Table 2. Publications of PFP in Journals Between 2002 and 2012

\begin{tabular}{|c|c|c|c|c|c|c|c|c|c|c|c|c|}
\hline Search Engine & 46 & 73 & 98 & 102 & 91 & 114 & 105 & 100 & 133 & 102 & 116 & 1072 \\
\hline CME & 2 & 4 & 5 & 5 & 3 & 2 & 5 & 3 & 6 & 6 & 4 & 45 \\
\hline IJPM & 3 & 2 & 2 & 2 & 5 & 2 & 2 & 2 & 2 & 0 & 1 & 23 \\
\hline ECAM & 0 & 3 & 1 & 5 & 3 & 3 & 2 & 1 & 0 & 3 & 1 & 22 \\
\hline
\end{tabular}

industry. On the other hand, the results from search engine have varied quite a lot, in other words, the number of PFP publications in 2012 is almost three times of that in 2002 . One of the potential reasons for this could be that researches published in the leading journals have a remarkable impact on related academia. Motivated by those research efforts of mainstream literatures, an increasing number of PFP-related papers have come out, indicating the increasing interest PFPs have aroused in the academic world.

\section{Active Contributors to Target Papers}

As mentioned in previous section, each target paper was given one score, which would be allocated to each author due to its contribution by (Table 1) when there are several authors. For instance, Zhang, Chen and Lim from the United States published one paper with cooperation of Qian from China, and the score for each individual author is $0.42,0.28$, 0.18 and 0.12 respectively, with scores of 0.88 and 0.12 separately awarded to the United States and China according to the calculation method this paper adopted. Measuring in this way, the country origin, affiliation, active authors and their contributions to the PFPs research will be discussed in more details in the following paragraphs.

Table 3 presents all the research origins of target PFP papers, along with the number of research centers, researchers, identified papers, and score for each research origin. It is obvious that the United States scored top with 40.53, with 110 researchers from 30 research centers getting involved in 49 papers. The United Kingdom comes second with a score of 18.83. It is worth highlighting that research origins with most contributions to PFP researches shown in (Table 3) are mostly from the developed world, such as the United States, the United Kingdom, Australia, and Hong Kong. China is an exception which ranks No. 4 in the list but is a developing country. It is not surprising because for the past decade, China has been dedicated to the improving of public service, and in that process, plenty of practical challenges from the real world encourage the researchers to explore issues on PFPs. The top five countries cover most of the publications, with the coverage of almost $69 \%$. There are good reasons for this concentration of publications. One of them may be that the national economics, construction education, awareness of PFPs, or low English literacy may contribute to the fact that developing countries seem to be less active in producing and publishing PFP papers.
As shown in (Table 3), statistics demonstrate that an increasing number of authors from different research centers all across the globe have been participating in the study of PFPs. Information provided by (Tables 4 and 5 ) further confirmed this conclusion. The analysis evinces that 13 authors got involved in more than one papers and 9 research centers contributed with a score of more than 3 points. This can be considered a sign that the research of PFPs is gathering ground and relative researchers are deepening and widening their research area to gradually make PFPs become their keystone, accompanied by formation of leading research centers. Among the most active authors, X.Q. Zhang from The Ministry of Water Resources of China who ever studied at The University of Hong Kong and The Hong Kong University of Science and Technology, published 6 papers on his own. And S.T. Ng from The University of Hong Kong contributed to 8 papers, most of which were cooperated with other researchers from his affiliation, such as Kumaraswamy M.M. who ranks in the third place of the most active researchers. Due to the efforts of these researchers, their research centre, The University of Hong Kong, also obtained the best ranking. The Hong Kong Polytechnic University is involved in 15 papers with a score of 5.54, followed by Queensland University of Technology, Australia of 4.59, and The Ministry of Water Resources of China of 4 . It should be highlighting that research centers in the United States and United Kingdom, the two most active country-contributors, seems to have relatively low ranking in (Table 5). The reason is that the numbers of research centers involved in the target papers of those countries are quite larger, 30 and 22 respectively, and that makes each of them contributes relatively less. This fact also implies that research interest on PFPs is widespread in the United States and United Kingdom. There is another fact which is worth noting that many individual researchers have also contributed to PFP publications a lot. In total 58 researchers from private practice participate into the publishing of those target papers, which gives more evidence to support the fact that PFP issues are the major concern of whole human society.

When referring to any factual material which is not original, it's recommended for the authors to cite a reference from the primary source. Besides, research findings can be well supported by suitable references [2]. As a result, it's important to analyze citation of selected papers to further appraisal the contributions of a specific author and its publications. 
Table 3. Research Origin of PFP Papers Published

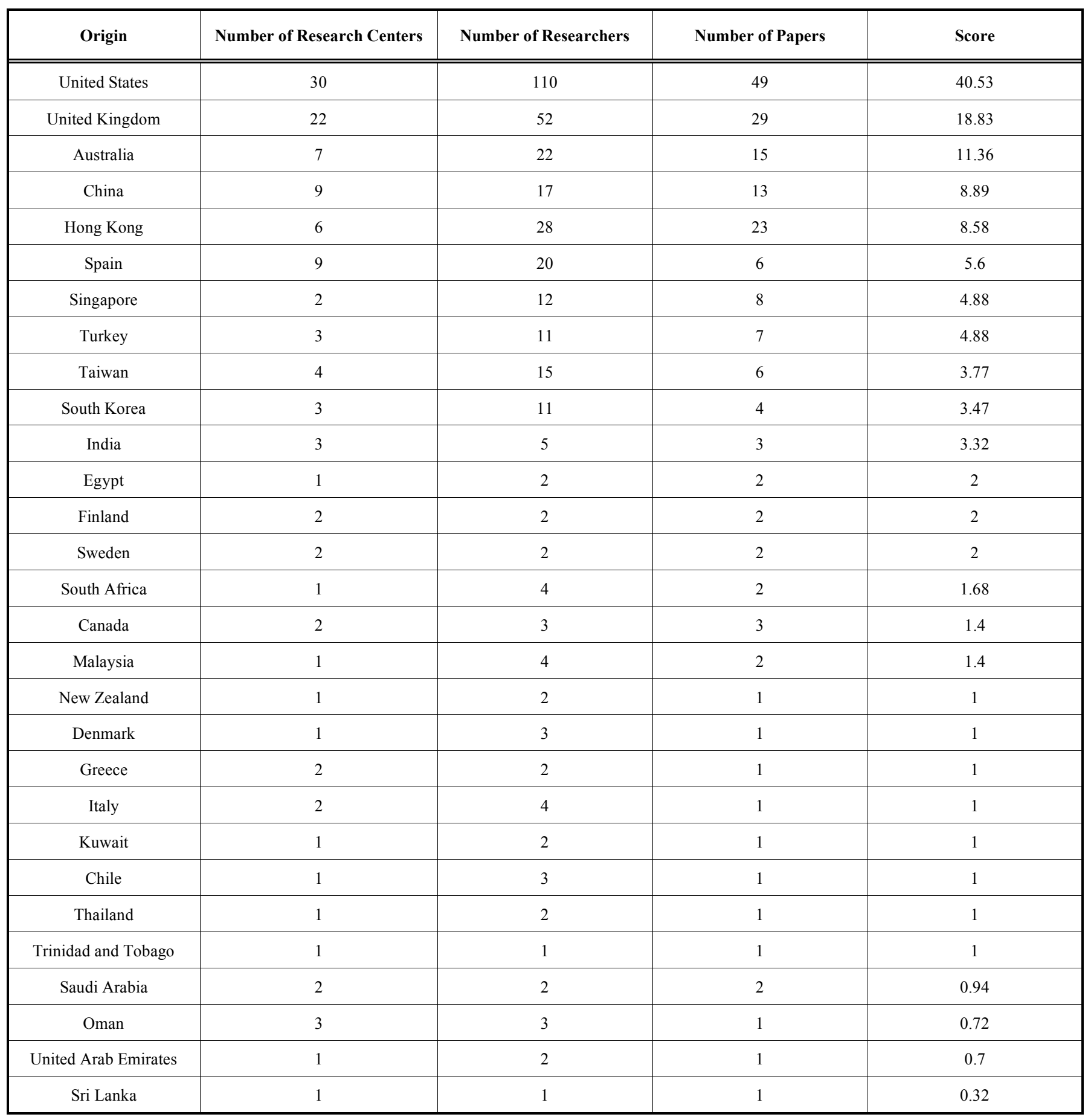

Most frequently cited papers are listed in (Table 6). Providing an in-depth and well-designed approach to select tenders for public office buildings adopting fuzzy MCDM method, the paper of Hsieh et al. [33] has been cited the most among the target papers with the number of 124 . The research team lead by Li in the United Kingdom produced two of the most frequently cited papers $[34,35]$. It should be highlighting that although citations reveal the impact one paper has in the research field; such reflection takes a while to present itself. That is why almost each paper in this list of most citation was published in the first half of the chosen research period.
Among the selected journals, IJPM has been cited most for 665 times, followed by 368 in JCEM and 321 in CME. With respect to times cited per PFP paper, the selected journals ranges from 1.8 to 28.91 as shown in (Table 7 ).

\section{Research Themes in PFP}

After comprehensive examination, this study identified eight groups of most popular research themes in PFPs in accordance with target publications including (1) integration research; (2) delivery method; (3) sustainable exploration; (4) governance issue; (5) financial concern; (6) performance 
Table 4. Authors Scored More Than One

\begin{tabular}{|c|c|c|c|c|}
\hline Zhang X.Q. & $\begin{array}{l}\text { The Ministry of Water Resources of China, The University of Hong } \\
\text { Kong, The Hong Kong University of Science and Technology }\end{array}$ & China & 6 & 6 \\
\hline Ng S.T. & The University of Hong Kong & Hong Kong & 8 & 2.99 \\
\hline Kumaraswamy M.M. & The University of Hong Kong & Hong Kong & 6 & 2.08 \\
\hline Ling F.Y.Y. & National University of Singapore & Singapore & 3 & 1.38 \\
\hline Arditi D. & Illinois Institute of Technology & United States & 4 & 1.36 \\
\hline Skitmore M. & Queensland University of Technology & Australia & 3 & 1.32 \\
\hline Wong J.M.W. & The University of Hong Kong & Hong Kong & 3 & 1.21 \\
\hline Sohail M. & Loughborough University & United Kingdom & 2 & 1.2 \\
\hline Tabish S.Z.S. & India Institute of Technology Delhi & India & 2 & 1.2 \\
\hline Lee E.B. & University of California at Berkeley & United States & 2 & 1.07 \\
\hline
\end{tabular}

Table 5. Affiliations with Highest Scores

\begin{tabular}{|c|c|c|c|}
\hline Affiliation & Country & Authors & Number of Papers \\
\hline \hline The University of Hong Kong & Hong Kong & 8 & 24 \\
\hline The Hong Kong Polytechnic University & Hong Kong & 12 & 15 \\
\hline Queensland University of Technology & Australia & 8 & 10 \\
\hline The Ministry of Water Resources of China & China & 1 & 4 \\
\hline National University of Singapore & Singapore & 6.08 & 8 \\
\hline Loughborough University & United Kingdom & 7 & 10 \\
\hline University of Texas & United States & 7 & 7 \\
\hline Istanbul Technical University & Turkey & 8 & 3.85 \\
\hline University of Washington & United States & 4 & 3.5 \\
\hline
\end{tabular}

study; (7) risk management; and (8) decision-making challenge. More detailed contents in each of these research themes are described as follows:

1. Integration research: knowledge integration and innovation, positive and negative factors, public policies, value management, research reviews in PFPs, and other related topics not included in other catalogues;

2. Delivery method: comparison of different deliveries of PFPs, improvement and optimization of the delivery method, selection and management of contractors, and contracting types;

3. Sustainable exploration: sustainability evaluation of PFPs, safety of workers, sustainable goal and development, social impact, emission assessment, environmental considerations, and techniques to achieve sustainability;
4. Governance issue: management skills, public participation, interface management, cooperation of stakeholders, claim management, and external program management;

5. Financial concern: assessment of cost and profit, economic and financial viability, tariff adjustment strategies, funding source and allocation, and pricing tools and index;

6. Performance study: key performance indicators, performance objectives, whole life performance assessment, and performance in different dimensions;

7. Risk management: risk identification and ranking, risk evaluation, risk allocation, risk sharing mechanism, risk prediction, response to risk, and risk of price cap; 
Table 6. Most Frequently Cited Papers

\begin{tabular}{|c|c|c|}
\hline Hsieh et al. [33] & Fuzzy MCDM approach for planning and design tenders selection in public office buildings & 124 \\
\hline Li et al. [34] & The allocation of risk in PPP/PFI construction projects in the UK & 92 \\
\hline Ng et al. [37] & Problematic issues associated with project partnering - the contractor perspective & 65 \\
\hline Naoum [39] & An overview into the concept of partnering & 52 \\
\hline Akintoye et al. [40] & Achieving best value in private finance initiative project procurement & 46 \\
\hline Pheng and Chuan [41] & Environmental factors and work performance of project managers in the construction industry & 42 \\
\hline Shen et al. [29] & Role of public private partnerships to manage risks in public sector projects in Hong Kong & 27 \\
\hline Kumaraswamy and Morris [44] & Build-operate-transfer-type procurement in Asian megaprojects & 26 \\
\hline
\end{tabular}

Table 7. Most Frequently Cited Journals

\begin{tabular}{|c|c|c|}
\hline Journal & Total Times & Times per Paper \\
\hline \hline International Journal of Project Management & 665 & 28.91 \\
\hline Journal of Construction Engineering and Management & 368 & 321 \\
\hline Construction Management and Engineering & 122 & 7.13 \\
\hline Engineering, Construction and Architectural Management & 54 \\
\hline Transportation Research Record & 5.55 \\
\hline
\end{tabular}

8. Decision-making challenge: decision-making techniques, decision-making model, decision-making support system, decision optimization, and impacts of market on decision-making.

There may be doubts on reliability of the grouping of research themes since identification and classification of them in each paper will be affected by readers' subjective opinions. In fact, researchers in this study analyzed each paper with the same criterion, and abundant discussion was proceeded to reach consensus when discrepancy happened, so any variations in views could be eliminated. Besides, this study aims at comparing and finding out common grounds of the target papers, therefore the approach adopted here is believed appropriate to achieve the goal. Through the research design, the major research themes in PFP between 2002 and 2012 obtained from target publications are provided in (Table 8). In order to present the distribution of research themes, (Fig. 2) is provided to demonstrate visual understanding.

Through a closer look at the target papers, some similarities are observed: they can be grouped into three catalogues, field report (72), theoretical analysis (49), and quantitative calculation (38) respectively. The numbers of publications in each catalogue and the proportions of each one are demonstrated in (Fig. 3). It is natural for the research in a certain area to develop from exploratory analysis aiming to find out some basic status and facts, to deeper discussion and modeling with more advanced techniques. In response to this common procedure, the target papers published relatively earlier tend to adopt more qualitative methodologies to conduct the researches, which have them grouped into the catalogues of field report and theoretical analysis. Researches targeting at producing field reports normally start with introducing the background and macro-context of the selected PFP [45], review existing literatures [46], then move to investigate current situation through qualitative methods such as empirical study [47], questionnaire [48], survey [49], indepth interview [50], focus group meeting [51], workshop [52], and comparative study [53], and end up with summary of existing problems and solutions [54], as well as suggestions of the authors [44]. Considering the study of Rosner et al. [55], under the situation that design-build (DB) method continues to grow for delivering construction project in both 
Table 8. Major Research Themes of PFP Papers

\begin{tabular}{|c|c|c|c|c|c|c|c|c|c|c|c|c|}
\hline Integration research & 1 & 1 & 5 & 4 & 3 & 3 & 1 & 5 & 4 & 2 & 1 & 30 \\
\hline Sustainable exploration & 1 & 2 & 1 & 1 & 3 & 4 & 2 & 1 & 4 & 1 & 5 & 25 \\
\hline Performance study & 2 & 1 & 2 & 2 & 1 & 0 & 0 & 3 & 0 & 3 & 0 & 14 \\
\hline Risk management & 1 & 0 & 0 & 3 & 3 & 0 & 1 & 1 & 1 & 1 & 0 & 11 \\
\hline Decision-making challenge & 0 & 0 & 2 & 0 & 1 & 2 & 1 & 0 & 0 & 0 & 1 & 7 \\
\hline
\end{tabular}

Fig. (2). Distribution of Research Themes.

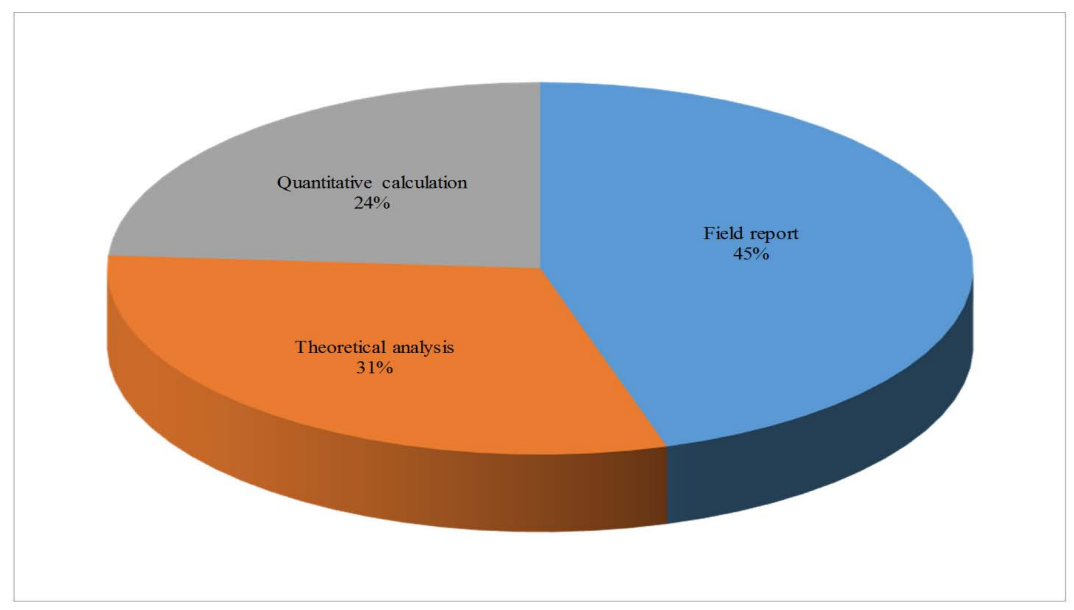

Fig. (3). Distribution of Research Theme Catalogues.

the private and public sector, the researchers chose to validate this delivery method in a special kind of PFPs, military construction programs. They compared the DB method with traditional design-bid-build (DBB) approach through 835 military construction programs to find out the DB method had better performance in three of six metrics and it was best suited for various facility types. Those of theoretical analysis go a little further by conducting exploratory qualitative research [56], revealing the relationships between research objectives [57], producing theoretical models [58], and establishing problem-solving framework[59]. In Nitithamyong and Tan's research [60], they investigated the important roles 
of project management consulting firms (PMCs), the key factors contributing to their effective performance and the suitable assessment criterion for performance through literature review and questionnaire survey, and established a framework of key success factors for achieving satisfying PMC performance. There are quite a lot of papers which adopted more complicated and vigorous quantitative methods to address problems in PFPs. The methods and techniques they employed are various, such as hedonic modeling [61], stochastic frontier regression modeling [62], structural equation modeling [63], critical path method and Monte Carlo simulation [64], artificial neural network and genetic algorithm [65], generic computer aided modeling [66], etc. Adopting the Carnegie Mellon University economic inputoutput life cycle assessment model, the research of Zhou et al. [67] is aimed at contributing to the sustainable development of PFPs by addressing environmental issues with reduced energy use and emissions in the process of construction. It is obvious that in the researches of PFPs, the number of attractive research themes is increasing, while the research methods are more in-depth to reveal the nature of the problems and contribute to PFPs practice.

It is worth highlighting that no matter what kind of issues a paper addresses, there is a word which appears quite frequently: sustainability. Except for those directly set sustainable goals [52], address social impact [68, 69], environmental considerations [41, 70], economic effect [71], as well as evaluate sustainability performance $[72,73]$ and promote sustainable development [74], many other authors also bear in mind one thing in common: sustainability should be one of the most vital characteristics of PFPs. Only through sustainable delivery of sustainable PFPs can help to reduce the negative impacts of the projects and the construction industry on the society [75-77]. However, investigations into current practice may reveal that sustainable construction of sustainable PFPs hasn't been achieved, which leaves a lot for the academia to explore $[67,78]$. Based on this discussion, there is no doubt that how to manage sustainability challenges in PFPs is the leading trend in this research field. Both researchers and practitioners relating to PFPs shall make more efforts to properly amplify, identify, process and manage sustainability issues in different life-cycle stages of PFPs. Managing sustainability challenges in PFPs is not only an edge-cutting topic, but also potential main contributor to the acceptable utility of valuable public investment. Filling of this research gap will demonstrate significance in theory, practice and industry as well.

\section{CONCLUSIONS}

Under the challenges of increasing demand of public services versus declining public investment in our society, the research in Public Funded Projects has been gaining more and more attention all over the world. To identify the trend of the research field, this study, from a perspective of construction management, conducted a three-round literature review of papers published between 2002 and 2012 in the field of Public Funded Projects. The initial scope of the publications was laid out by the search engine Scopus using a combination of terms in title, abstract and keywords, followed by a further confirmation of target papers in selected journals and a comprehensive visual examination.
Researchers from different countries and jurisdictions have contributed durative efforts to review international Public Funded Projects practices and seek for appropriate approaches to promote better implementation. 159 papers were identified in five selected academic journals published between 2002 and 2012. Through the content analysis of the target publications, and with support of solid evidence in the papers, the importance of Public Funded Projects is more than easy to tell. The United States scored most among all the research origins, followed by the United Kingdom, Australia, China, Hong Kong, and Spain. With respect to research institutions, The University of Hong Kong, The Hong Kong Polytechnic University, Queensland University of Technology in Australia, and The Ministry of Water Resources of China was ranked to be the most resourceful contributors, thanks to their active researchers persistently exploring Public Funded Projects. Ranking of active authors and institutions can probably provide good potential for cooperation of practitioners and scholars.

By means of comprehensive content examination, papers concerning Public Funded Project can be grouped into three catalogues, namely field report, theoretical analysis, and quantitative calculation. Field report reflecting practices of the real world set the foundation for the other two groups, while theoretical analysis as well as quantitative calculation provides strategies and viable approaches to improve the performance of Public Funded Projects through profound theories and vigorous models and technologies. This study also summarized eight groups of most popular research themes in Public Funded Projects from target publications including (1) integration research; (2) delivery method; (3) sustainable exploration; (4) governance issue; (5) financial concern; (6) performance study; (7) risk management; and (8) decision-making challenge. Implied by the mainstream themes, the future research trend in Public Funded Projects will be led by sustainable explorations on improving the sustainability performance of the projects in every stage of life-cycle. As a result, how to manage the sustainability challenges for Public Funded Projects is the emerging research focus in this area.

This study has provided an overall review of researches on Public Funded Projects in academia and thereby built a concrete platform for further study of other researchers with similar interests. Understanding the major research themes and research trend in Public Funded Projects may enable both the researchers and practitioners to explore key issues obstructing development of Public Funded Projects and hence be of great value for the whole industry. For those in need, additional readings of PFP can be found in the list of the most cited papers.

\section{CONFLICT OF INTEREST}

The author(s) confirm that this article content has no conflicts of interest.

\section{ACKNOWLEDGEMENT}

Declared none. 


\section{REFERENCES}

[1] A. Marsay, "Sustainable transport infrastructure investment: a case study for South Africa: Transportation Engineering," vol. 17, no. 8, pp. 1-9, 2009

[2] Y. Ke, S. Wang, A. Chan, and E. Cheung, "Research Trend of Public-Private Partnership in Construction Journals," Journal of Construction Engineering and Management, vol. 135, pp. 10761086, 2009.

[3] M. H. Lee, Y. T. Wu, and C. C. Tsai, "Research Trends in Science Education from 2003 to 2007: A content analysis of publications in selected journals," International Journal of Science Education, vol. 31, pp. 1999-2020, 2009.

[4] C. C. Tsai, and M. Lydia Wen, "Research and trends in science education from 1998 to 2002: a content analysis of publication in selected journals," International Journal of Science Education, vol. 27, pp. 3-14, 2005.

[5] E. J. Ki, and J. H. Shin, "Status of organization-public relationship research from an analysis of published articles, 1985-2004," Public Relations Review, vol. 32, pp. 194-195, 2006

[6] A. Pilkington, and K. H. Chai, "Research themes, concepts and relationships: A study of International Journal of Service Industry Management (1990-2005)," International Journal of Service Industry Management, vol. 19, pp. 83-110, 2008.

[7] M. Bresnen, and N. Marshall, "Partnering in construction: a critical review of issues, problems and dilemmas," Construction Management \& Economics, vol. 18, pp. 229-237, 2000.

[8] F. Al-Sharif, and A. Kaka, "PFI/PPP topic coverage in construction journals," presented at the 20th Annual ARCOM Conference, Heriot Watt University, Edinburgh, Scotland, UK, 2004.

[9] H. Yuan, and L. Shen, "Trend of the research on construction and demolition waste management," Waste Management, vol. 31, pp. 670-679, 2011.

[10] B. Flyvbjerg, M. K. Skamris holm, and S. L. Buhl, "How common and how large are cost overruns in transport infrastructure projects?," Transport Reviews, vol. 23, pp. 71-88, 2003.

[11] K. Honek, E. Azar, and C. C. Menassa, "Recession Effects in the United States Public Sector Construction Contracting: Focus on American Recovery and Reinvestment Act of 2009," Journal of Management in Engineering, vol, 28, no. 4, pp. 354-361, 2011.

[12] U. S. C. Bureau. (2012, February 20, 2013). Construction Spending. Available: http://www.census.gov/construction/c30/ c30index.html

[13] R. Board. (2010, February 20, 2013). The Recovery Act. Available: http://www.recovery.gov/About/Pages/The_Act.aspx

[14] S. Singh, Building a 21st Century South Africa. Researching the Infrastructure Inputs Sector Strategy for AsgiSA, The Presidency of the Government of South Africa and Suedo IBC: Pretoria, 2007.

[15] WorldBank, Private Participation in Infrastructure Database, WorldBank PPIAF: Washington DC, 2013.

[16] C. Ebdon and P. Landow, "The Balancing Act: Using Private Money for Public Projects," Public Budgeting \& Finance, vol. 32, pp. $58-79,2012$.

[17] J. Cusworth and T. Franks, Managing projects in developing countries, Longman Group Limited, Longman Scientific \& Technical, UK, 1993.

[18] W. C. Baum and S. M. Tolbert, Investing in development: Lessons of World Bank experience, Cambridge Univ Press, Cambridge, 1985.

[19] J. R. Bartle, "Coping with cutbacks: City response to aid cuts in New York state," State \& Local Government Review, pp. 38-48, 1996.

[20] P. Choate and S. Walter, America in ruins: Beyond the public works pork barrel, Council of State Planning Agencies: Washington, DC, 1981.

[21] K. Divakar and K. Subramanian, "Critical success factors in the real-time monitoring of construction projects," Research Journal of Applied Sciences, Engineering and Technology, vol. 1, pp. 35-39, 2009.

[22] S. Z. S. Tabish and K. N. Jha, "Identification and evaluation of success factors for public construction projects," Construction Management and Economics, vol. 29, pp. 809-823, 2011.

[23] K. V. Thai, International handbook of public procurement vol. 146, Auerbach Publications, USA, 2008.
[24] F. Emuze and J. J. Smallwood, "Bridging public works project performance gaps in South Africa," Proceedings of the ICEManagement, Procurement and Law, vol. 165, pp. 111-118, 2012.

[25] O. J. Klakegg and T. Haavaldsen, "Governance of major public investment projects: in pursuit of relevance and sustainability," International Journal of Managing Projects in Business, vol. 4, pp. 157-167, 2010.

[26] K. Samset, Project evaluation: making investments succeed: Tapir Forlag, 2003.

[27] P. A. Bowen, P. J. Edwards, and K. Cattell, "Corruption in the South African construction industry: A thematic analysis of verbatim comments from survey participants," Construction Management and Economics, vol. 30, pp. 885-901, 2012.

[28] X. Zhang, "Financial viability analysis and capital structure optimization in privatized public infrastructure projects," Journal of Construction Engineering and Management, vol. 131, pp. 656$668,2005$.

[29] L. Y. Shen, A. Platten, and X. P. Deng, "Role of public private partnerships to manage risks in public sector projects in Hong Kong," International Journal of Project Management, vol. 24, pp. 587-594, 2006

[30] M. E. Falagas, E. I. Pitsouni, G. A. Malietzis, and G. Pappas, "Comparison of PubMed, Scopus, web of science, and Google scholar: strengths and weaknesses," The FASEB Journal, vol. 22, pp. 338-342, 2008.

[31] K. W. Chau, "The ranking of construction management journals," Construction Management \& Economics, vol. 15, pp. 387-398, 1997.

[32] G. S. Howard, D. A. Cole, and S. E. Maxwell, "RESEARCH PRODUCTIVITY IN PSYCHOLOGY BASED ON PUBLICATION IN THE JOURNALS OF THE AMERICANPSYCHOLOGICAL-ASSOCIATION," American Psychologist vol. 42, pp. 975-986, Nov 1987.

[33] T. Y. Hsieh, S. T. Lu, and G. H. Tzeng, "Fuzzy MCDM approach for planning and design tenders selection in public office buildings," International Journal of Project Management, vol. 22, pp. 573-584, 2004

[34] B. Li, A. Akintoye, P. J. Edwards, and C. Hardcastle, "The allocation of risk in PPP/PFI construction projects in the UK," International Journal of Project Management, vol. 23, pp. 25-35, 2005.

[35] B. Li, A. Akintoye, P. J. Edwards, and C. Hardcastle, "Perceptions of positive and negative factors influencing the attractiveness of $\mathrm{PPP} / \mathrm{PFI}$ procurement for construction projects in the UK: Findings from a questionnaire survey," Engineering, Construction and Architectural Management, vol. 12, pp. 125-148, 2005

[36] D. Grimsey and M. K. Lewis, "Evaluating the risks of public private partnerships for infrastructure projects," International Journal of Project Management, vol. 20, pp. 107-118, 2002.

[37] S. T. Ng, T. M. Rose, M. Mak, and S. E. Chen, "Problematic issues associated with project partnering - the contractor perspective," International Journal of Project Management, vol. 20, pp. 437449, 2002.

[38] X. Zhang, "Critical success factors for public-private partnerships in infrastructure development," Journal of Construction Engineering and Management, vol. 131, pp. 3-14, 2005.

[39] S. Naoum, "An overview into the concept of partnering," International Journal of Project Management, vol. 21, pp. 71-76, 2003.

[40] A. Akintoye, C. Hardcastle, M. Beck, E. Chinyio, and D. Asenova, "Achieving best value in private finance initiative project procurement," Construction Management and Economics, vol. 21, pp. 461-470, 2003.

[41] L. S. Pheng and Q. T. Chuan, "Environmental factors and work performance of project managers in the construction industry," International Journal of Project Management, vol. 24, pp. 24-37, 2006

[42] M. J. Garvin and C. Y. J. Cheah, "Valuation techniques for infrastructive investment decisions," Construction Management and Economics, vol. 22, pp. 373-383, 2004.

[43] D. W. M. Chan and M. M. Kumaraswamy, "Compressing construction durations: Lessons learned from Hong Kong building projects," International Journal of Project Management, vol. 20, pp. 23-35, 2002. 
[44] M. M. Kumaraswamy and D. A. Morris, "Build-operate-transfertype procurement in Asian megaprojects," Journal of Construction Engineering and Management, vol. 128, pp. 93-102, 2002.

[45] E. Garbin and J. A. Mann, "Mass stabilization for environmentally sensitive projects in Florida," Journal of Transportation Research Board, vol. 2201, pp. 62-69, 2010.

[46] K. Moodley, N. Smith, and C. N. Preece, "Stakeholder matrix for ethical relationships in the construction industry," Construction Management and Economics, vol. 26, pp. 625-632, 2008.

[47] M. C. A. Balatbat, C. Y. Lin, and D. G. Carmichael, "Comparative performance of publicly listed construction companies: Australian evidence," Construction Management and Economics, vol. 28, pp. 919-932, 2010.

[48] C. S. Poon, A. T. W. Yu, and L. H. Ng, "Comparison of low-waste building technologies adopted in public and private housing projects in Hong Kong," Engineering, Construction and Architectural Management, vol. 10, pp. 88-98, 2003.

[49] E. M. Rojas, "Single versus multiple prime contracting," Journal of Construction Engineering and Management, vol. 134, pp. 758-765, 2008.

[50] W. L. Tzeng, J. C. C. Li, and T. Y. Chang, "A study on the effectiveness of the most advantageous tendering method in the public works of Taiwan," International Journal of Project Management, vol. 24, pp. 431-437, 2006.

[51] A. M. Anvuur, M. M. Kumaraswamy, and G. Mahesh, "Building relationally integrated value networks (RIVANS)," Engineering, Construction and Architectural Management, vol. 18, pp. 102-120, 2011.

[52] W. Swan, and M. M. A. Khalfan, "Mutual objective setting for partnering projects in the public sector," Engineering, Construction and Architectural Management, vol. 14, pp. 119-130, 2007.

[53] M. Skitmore, and H. Smyth, "Pricing construction work: A marketing viewpoint," Construction Management and Economics, vol. 25, pp. 619-630, 2007.

[54] L. H. Orcutt, and M. Y. Alkadri, "Overcoming roadblocks to innovation: Three case studies at the California department of transportation," Journal of Transportation Research Board, pp. 6573, 2009.

[55] J. W. Rosner, A. E. Thal Jr, and C. J. West, "Analysis of the design-build delivery method in air force construction projects," Journal of Construction Engineering and Management, vol. 135, pp. 710-717, 2009.

[56] H. Smyth, "The credibility gap in stakeholder management: Ethics and evidence of relationship management," Construction Management and Economics, vol. 26, pp. 633-643, 2008.

[57] X. Ruan, E. G. Ochieng, A. D. F. Price, and C. O. Egbu, "Knowledge integration process in construction projects: a social network analysis approach to compare competitive and collaborative working," Construction Management and Economics, vol. 30, pp. 5-19, 2012.

[58] R. Gerbrandt and C. Berthelot, "Life-cycle economic evaluation of alternative road construction methods on low-volume roads," Journal of Transportation Research Board, vol. 1, , pp. 61-71, 2007.

[59] D. N. Sillars, and J. Riedl, "Framework model for determining incentive and disincentive amounts," Journal of Transportation Research Board, pp. 11-18, 2007.

[60] P. Nitithamyong, and Z. Tan, "Determinants for effective performance of external project management consultants in Malaysia," Engineering, Construction and Architectural Management, vol. 14, pp. 463-478, 2007.

[61] K. Kittrell, "Impacts of vacant land values," ed, 2012, pp. 138-145.
[62] K. Duncan, P. Philips, and M. Prus, "Using stochastic frontier regression to estimate the construction cost inefficiency of prevailing wage laws," Engineering, Construction and Architectural Management, vol. 19, pp. 320-334, 2012.

[63] S. Z. S. Tabish, and K. N. Jha, "The impact of anti-corruption strategies on corruption free performance in public construction projects," Construction Management and Economics, vol. 30, pp. 21-35, 2012.

[64] X. Zhang, "Win-win concession period determination methodology," Journal of Construction Engineering and Management, vol. 135, pp. 550-558, 2009.

[65] O. S. Al-Sobiei, D. Arditi, and G. Polat, "Predicting the risk of contractor default in Saudi Arabia utilizing artificial neural network (ANN) and genetic algorithm (GA) techniques," Construction Management and Economics, vol. 23, pp. 423-430, 2005.

[66] E. Tas, and H. Yaman, "A building cost estimation model based on cost significant work packages," Engineering, Construction and Architectural Management, vol. 12, pp. 251-263, 2005.

[67] Y. Zhou, L. Tupper, M. Chowdhury, and L. Klotz, "Green credits versus environmentally sustainable traffic operations: Comparison of contributions to energy and emissions reductions," Journal of Transportation Research Board, pp. 103-111, 2010.

[68] M. Zhang, "Can transit-oriented development reduce peak-hour congestion?," Journal of Transportation Research Board, pp. 148155,2010 .

[69] G. Lizarralde and D. Root, "The informal construction sector and the inefficiency of low cost housing markets," Construction Management and Economics, vol. 26, pp. 103-113, 2008.

[70] G. Christini, M. Fetsko, and C. Hendrickson, "Environmental management systems and ISO 14001 certification for construction firms," Journal of Construction Engineering and Management, vol. 130, pp. 330-336, 2004.

[71] S. Gundes, "Exploring the dynamics of the turkish construction industry using input-output analysis," Construction Management and Economics, vol. 29, pp. 59-68, 2011.

[72] A. Horsley, C. France, and B. Quatermass, "Delivering energy efficient buildings: A design procedure to demonstrate environmental and economic benefits," Construction Management and Economics, vol. 21, pp. 345-356, 2003.

[73] A. Aguado, A. D. Caño, M. P. De La Cruz, D. Gómez, and A. Josa, "Sustainability assessment of concrete structures within the Spanish structural concrete code," Journal of Construction Engineering and Management, vol. 138, pp. 268-276, 2012.

[74] G. C. S. Puthamont, and C. Charoenngam, "Strategic project selection in public sector: Construction projects of the Ministry of Defence in Thailand," International Journal of Project Management, vol. 25, pp. 178-188, 2007.

[75] W. Orabi, and K. El-Rayes, "Optimizing the rehabilitation efforts of aging transportation networks," Journal of Construction Engineering and Management, vol. 138, pp. 529-539, 2012.

[76] A. McCabe, R. Parker, and K. Brown, "Social outcomes in the construction industry: The case of the Western Australian 'percent for art' policy," Construction Management and Economics, vol. 29, pp. 929-941, 2011.

[77] R. Pellegrino, L. Ranieri, N. Costantino, and G. Mummolo, "A real options-based model to supporting risk allocation in price cap regulation approach for public utilities," Construction Management and Economics, vol. 29, pp. 1197-1207, 2011.

[78] M. Jefferies, and W. D. McGeorge, "Using public-private partnerships (PPPs) to procure social infrastructure in Australia," Engineering, Construction and Architectural Management, vol. 16, pp. 415-437, 2009.

\author{
Received: May 05, 2013 \\ Revised: July 11, 2013 \\ Accepted: July 11, 2013 \\ (C) Yi and Wang; Licensee Bentham Open.
}

This is an open access article licensed under the terms of the Creative Commons Attribution Non-Commercial License (http://creativecommons.org/licenses/by-nc/3.0/) which permits unrestricted, non-commercial use, distribution and reproduction in any medium, provided the work is properly cited. 